\title{
Assessment of Endothelial cell Density in Pterygium: \\ A Cross-sectional Study
}

\section{Short title: Endothelial cell Density in Pterygium \\ Mohamed Yasser Sayed Saif ${ }^{1}$, Mohamed Ragab Sabra² , Ahmed Taha Gouda $^{1}$}

${ }^{1}$ Department of Ophthalmology, Faculty of Medicine, Beni-Suef University, Beni-Suef, Egypt

${ }^{2}$ Department of Ophthalmology, Faculty of Medicine, Sohag University, Sohag, Egypt

Email: Ahmedelgebaly94@gmail.com

\begin{abstract}
Background: Recent reports suggested that pterygium significantly alters corneal endothelium cell density. We performed this study to evaluate the changes in corneal endothelium cell density in patients with pterygium.

Methods: A cross-sectional, comparative, study was conducted on 20 adults' patients (total 40 eyes) with unilateral pterygium and a good-quality endothelial cell count. The contralateral eye of each patient served as a control. The endothelial cell density was measured by specular microscope.

Results: The majority of patients were males with average age of $45 \pm 8$ years old. Astigmatism difference was of average $1.18 \pm 1.5$. Pterygium length ranged from 2 to 4 $\mathrm{mm}$ (mean $2.7 \pm 0.65 \mathrm{~mm}$ ), width ranged from 2 to $4 \mathrm{~mm}$ (mean $2.45 \pm 0.6 \mathrm{~mm}$ ) and pterygium size ranged from 4 to $12 \mathrm{~mm}^{2}$ (mean, $6.75 \pm 2.69 \mathrm{~mm}$ ). The Specular microscopy showed no statistically significant difference between eyes with pterygium and controls for endothelial cell density. The correlations between endothelial cell density and pterygium sizes were weak positive not statistically significant (P-value >0.05),

Conclusion: In conclusion, this comparative study showed that pterygium was associated with a decrease in corneal ECD but with statistical insignificant difference.

Keywords: Pterygium; endothelium cell density; comparative study.
\end{abstract}

\section{Introduction:}

Pterygium is a degenerative
conjunctival disorder that is
characterized by progressive invasion of
bulbar conjunctive into the cornea,
mainly in wedge-shaped form[1].
Previous epidemiological figures have
estimated that the global prevalence of
pterygium is about $10-12 \%$; however,
the incidence of pterygium varies
substantially according to geographical
area, race, sex, and other demographic
factors. For example, pterygium is more
prevalent in Asian and black American

populations with reported incidence of up to $30 \%[2,3]$. Over the past decades, various theories have been implicated in the pathogenesis of pterygium including inflammation-mediated disorder, sun exposure, and viral infection; nevertheless, the exact pathogenesis of pterygium is still largely unknown[4]. Patients with pterygium may present

Received : 5/5/2020

Accepted : 21/5/2020

Online publication : $1 / 6 / 2020$ 
with distressing symptoms such as redness, corneal irritation, dry eye, aesthetics issues, and deteriorated visual acuity. Thus, pterygium can significantly threaten patients' vision and affect their quality of life[5]. Surgical excision of pterygium is usually indicated in patients with significant visual disturbance. However, due to high recurrence rates with surgical treatment alone, adjunctive therapies have been introduced with promising reduction in recurrence rate[6].

Histopathologically,

the pterygium lesion begins with hyperplastic growth of limbal epithelial cells, which directed centrally along with fibroblastic stroma and modified matrix towards the Bowman's layer; which finally leads to degradation of Bowman's layer and wide-shaped lesion in superficial layer of cornea[4,7]. Although pterygium lesion is usually located within the superficial layers of cornea, it can trigger disturbance in hemidesmosome attachments due to stimulation of matrix metalloproteinase [8]. Therefore, recent reports have investigated the impact of pterygium lesion on deep layers of cornea, such as Descemet membrane and endothelium.

The corneal endothelium cell density (ECD) is an important feature of corneal endothelium that provides proper hydration to the cornea. The normal value of ECD in adults is 2500 cells $/ \mathrm{mm}^{2}$; based on previous observation, an ECD of less than 800 cells $/ \mathrm{mm}^{2}$ is a risk factor for corneal edema, with subsequent deterioration in vision[9]. Recently, it was suggested that patients with pterygium are at higher risks of reduced ECD[10]. Therefore, we conducted the present cross-sectional study in order to assess the effects of pterygium on corneal ECD using specular microscope.

\section{Materials and Methods:}

The present manuscript was prepared in concordance with the recommendations of Strengthening the Reporting of Observational studies in Epidemiology (STROBE)[11].

\section{Study Design and Patients:}

A hospital-based comparative study was conducted on 20 patients with pterygium who were recruited from Beni-suef University Hospital and the Memorial Institute of ophthalmology. Adults' patients with unilateral pterygium and a good-quality endothelial cell count of at least of 75 cells $/ \mathrm{mm}^{2}$. The contralateral eye of each patient served as a control. We excluded patients with history of ocular surgery, using contact lens in either eye, uveitis, keratitis, glaucoma, trauma, central cell count of $<1800$ cells $/ \mathrm{mm}^{2}$, or intraocular pressure of $>21 \mathrm{mmHg}$. Patients with diabetes mellitus were excluded as well.

The study's protocol was approved and registered by the local ethics committee of Beni-Suef University Hospital and the Memorial Institute of ophthalmology. Written informed consents were obtained from all patients prior to the study's enrollment.

\section{Data collection}

Eligible patients were assessed and the following data were collected from every eligible patient: demographic characteristics, mean corneal power $(\mathrm{KM})$ in the $3.00 \mathrm{~mm}$ central zone; corneal astigmatism in the $3.00 \mathrm{~mm}$ 
central zone(AST), ECD; coefficient of variation (CV); hexagonality (HEX), pachymetric results $(\mu \mathrm{m})$, and pterygium size.

The mean corneal power and corneal astigmatism were measured by auto keratometer. On the other hand, the ECD, CV, and HEX were measured by non-contact Topcon specular microscopy. The pterygium size including the horizontal extension onto cornea from the limbus, and the width of the base at the limbus, was measured with a slit lamp by using a slit beam of light (in millimeters).

\section{Study's outcomes:}

The primary outcome in the present study was the difference in ECD between pterygium and control groups. The secondary outcome was to assess the correlation between ECD and pterygium size.

Statistical Analysis:
All statistical analyses were performed using SPSS version 22.0 for Windows. Continuous data were expressed as mean $( \pm$ standard deviation [SD]) and categorical data were described as percentages. Independent ttest was used to assess the significance of the association between continuous variables and Chi-square was used for categorical data. The correlation coefficient was calculated. A P-values of less than 0.05 was considered statistically significant.

\section{Results:}

The majority of patients were males $(65 \%)$ with average age of $45 \pm 8$ years old. Astigmatism difference was of average $1.18 \pm 1.5 \quad(\mathrm{p} \quad=0.038)$. Pterygium length ranged from 2 to $4 \mathrm{~mm}$ (mean $2.7 \pm 0.65 \mathrm{~mm}$ ), width ranged from 2 to $4 \mathrm{~mm}$ (mean $2.45 \pm 0.6 \mathrm{~mm}$ ) and pterygium size ranged from 4 to $12 \mathrm{~mm}^{2}$ (mean, $6.75 \pm 2.69 \mathrm{~mm}$ ) (Table 1).

Table (1): Demographic and clinical characteristics among the studied eyes.

\begin{tabular}{|c|c|c|c|c|}
\hline Variables & & $\begin{array}{c}\text { Eyes With Pterygium } \\
(\mathbf{n = 2 0})\end{array}$ & $\begin{array}{c}\text { Control Eyes } \\
(\mathbf{n = 2 0})\end{array}$ & P-value \\
\hline Age & Mean \pm SD & $45 \pm 8$ & \\
\hline Male & Freq. (\%) & \multicolumn{2}{|c|}{$13(65 \%)$} & \\
\hline Astigmatism & Mean \pm SD & $-1.7 \pm 1.9$ & $-0.67 \pm 0.6$ & $0.038^{*}$ \\
\hline Rt. Side & Freq. (\%) & \multicolumn{2}{|c|}{$13(65 \%)$} & \\
\hline Length (mm) & Mean \pm SD & $2.7 \pm 0.65$ & \\
\hline Width (mm) & Mean \pm SD & $2.45 \pm 0.60$ & \\
\hline Size (mm $\left.\mathbf{m m}^{\mathbf{2}}\right)$ & Mean \pm SD & $6.75 \pm 2.69$ & \\
\hline
\end{tabular}

The Specular microscopy showed no statistically significant difference between eyes with pterygium and controls for endothelial cell density (P-value >0.05) (Table 2). 
Table (2): Specular microscopy of the studied patients.

\begin{tabular}{|c|c|c|c|c|}
\hline \multicolumn{2}{|c|}{ Specular microscopy } & $\begin{array}{l}\text { Eyes With } \\
\text { Pterygium }\end{array}$ & $\begin{array}{c}\text { Control Eyes } \\
(n=20)\end{array}$ & P-value \\
\hline \multirow{3}{*}{ CCT } & Mean \pm SD & $505 \pm 32$ & $503.3 \pm 26$ & \multirow[t]{3}{*}{$0.854^{1}$} \\
\hline & Range & $(437-557)$ & $(456-551)$ & \\
\hline & Median & 503 & 503.5 & \\
\hline \multirow{3}{*}{ ECD } & Mean \pm SD & $1271 \pm 1100$ & $1931 \pm 1103$ & \multirow[t]{3}{*}{$0.142^{1}$} \\
\hline & Range & $(459-3291)$ & $(456-3087)$ & \\
\hline & Median & 531.5 & 2488.5 & \\
\hline \multirow{3}{*}{ CV } & Mean \pm SD & $32.6 \pm 3.9$ & $31.3 \pm 3.8$ & \multirow[t]{3}{*}{$0.314^{1}$} \\
\hline & Range & $(27-40)$ & $(25-40)$ & \\
\hline & Median & 33 & 31 & \\
\hline \multirow{3}{*}{ HEX } & Mean \pm SD & $52.3 \pm 9$ & $54.4 \pm 8$ & \multirow[t]{3}{*}{$0.451^{1}$} \\
\hline & Range & $(30-68)$ & $(38-71)$ & \\
\hline & Median & 53.5 & 55.5 & \\
\hline
\end{tabular}

1. Mann Whitney U test; $\quad *$ Statistically significant at $p<0.05$.

The correlations between endothelial cell density and pterygium sizes were weak positive not statistically significant (P-value $>0.05$ ).

\section{Discussion:}

Although pterygium lesion is usually located within the superficial layers of cornea, it can trigger disturbance in hemidesmosome attachments due to stimulation of matrix metalloproteinase[8]. Therefore, recent reports have investigated the impact of pterygium lesion on deep layers of cornea, such as Descemet membrane and endothelium. Therefore, in this study, we aimed to assess the effects of pterygium on corneal ECD using specular microscope.

Our study demonstrated a numerically lower ECD in pterygium group than the control group; however, this difference did not reach the level of statistical significance. No differences were observed between cases and controls with regard to the mean $\mathrm{CV}$ of cell size, hexagonality, and central corneal thickness. Correlation between ECD and Pterygium sizes were weak positive \& not statistically significant. In contrary, it was shown by Sousa et al[12] that the ECD was lower in the pterygium eyes than in the controls. Another retrospective comparative study performed by Hsu et al[10] demonstrated a decrease in the corneal ECD in eyes with pterygium involvement.

In our study, astigmatism mean difference between both eyes of the studied eyes was of average 1.18 \pm 1.5 , with statistically significant difference between studied groups ( $p$-value $>0.05$ ). In line with our findings, Salih and Sharif[13] found a significantly higher value of corneal astigmatism in pterygium-affected eyes than control eyes. In similar Sousa et al[12] observed that the mean value of corneal 
astigmatism was significantly higher in the pterygium group than in the control group.

To our knowledge, there are few studies that addressed changes in ECD in pterygium. However, the study showed some limitations: 1) All patients recruited from two centers only; therefore, these results may not be generalized to all patients; 2) this was a comparative study and there was no follow-up, so we cannot document the long-term endothelial changes that may become evident over the long term; and 3) The number of patients included in this study was limited by availability.

\section{Conclusion}

In conclusion, compared with the contralateral eyes, this comparative study showed that pterygium was associated with a decrease in corneal ECD but with statistical insignificant difference. It is important that further longitudinal studies be conducted to find and confirm association between these two variables.

\section{Conflict of Interest:}

All authors confirm no financial or personal relationship with a third party whose interests could be positively or negatively influenced by the article's content.

\section{Acknowledgment:}

None

\section{References:}

1. Singh SK. Pterygium: epidemiology prevention and treatment. Community eye Heal [Internet]. 2017 [cited 2019 Nov 25];30:S5-6. Available from: http://www.ncbi.nlm.nih.gov/pubmed/29 849437

2. Liu L, Wu J, Geng J, Yuan Z, Huang D. Geographical prevalence and risk factors for pterygium: A systematic review and meta-analysis. BMJ Open. 2013;3.

3. Rezvan F, Khabazkhoob M, Hooshmand E, Yekta A, Saatchi M, Hashemi H. Prevalence and risk factors of pterygium: a systematic review and meta-analysis. Surv Ophthalmol. 2018;63:719-35.

4. Bradley JC, Yang W, Bradley RH, Reid TW, Schwab IR. The science of pterygia. Br J Ophthalmol. 2010;94:81520.

5. Chui J, Coroneo MT, Tat LT, Crouch R, Wakefield D, Di Girolamo N. Ophthalmic pterygium: A stem cell disorder with premalignant features. Am J Pathol. 2011;178:817-27.

6. Cornelius CR. Recurrence Rate and Complications of Pterygium Extended Removal Followed by Extended Conjunctival Transplant. Cornea. 2017;36:101-3.

7. Eze BI, Maduka-okafor FC, Okoye OI, Chuka-okosa CM. Pterygium: A review of clinical features and surgical treatment. Niger. J. Med. 2011. p. 7-14.

8. Todani A, Melki SA. Pterygium current concepts in pathogenesis and treatment. Int. Ophthalmol. Clin. 2009. p. 21-30.

9. Bourne WM, McLaren JW. Clinical responses of the corneal endothelium. Exp Eye Res. 2004;78:561-72.

10. Hsu MY, Lee HN, Liang CY, Wei LC, Wang CY, Lin KH, et al. Pterygium is related to a decrease in corneal endothelial cell density. Cornea. 2014;33:712-5.

11. Elm E Von, Altman DG, Egger M, 
Pocock SJ, Gøtzsche PC, Vandenbroucke JP, et al. The Strengthening the Reporting of Observational Studies in Epidemiology ( STROBE ) Statement: Guidelines for reporting observational studies *. Int $\mathbf{J}$ Surg. Elsevier Ltd; 2014;12:1495-9.

12. Sousa HCC, Silva LNP, Tzelikis PF. Corneal endothelial cell density and pterygium: A cross-sectional study. Arq Bras Oftalmol. 2017;80:317-20.

13. Mohammad-Salih PAK, Sharif AFMD. Analysis of pterygium size and induced corneal astigmatism. Cornea. 2008;27:434-8. 